\title{
MARKETING DE EXPERIÊNCIA
}

A experiência do consumidor é a variável chave da arquitetura da estratégia e da gestão em contextos de competitividade acirrada. A Era da Experiência surge do movimento natural de evolução das organizações que buscam novos atributos e benefícios que gerem e capturem valor mais expressivo, criando e gerenciando vínculos mais robustos do consumidor com suas marcas e produtos. Marketing de experiência versa sobre as especificidades técnicas na gestão do processo de troca de ofertas que têm como base do seu diferencial competitivo a superioridade na satisfação das necessidades emocionais do consumidor. As obras indicadas pela professora Martha Savastano, da FGV-EAESP aprofundam os conceitos relativos à emoção, experiência como o conjunto de sensações e a gestão dos pontos de contato do consumidor com o processo de compra que são primordiais para o entendimento do tema.

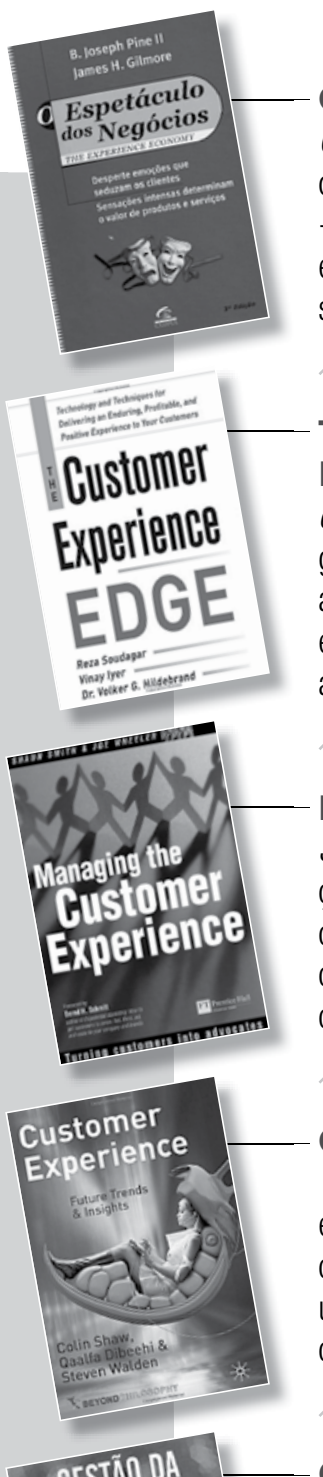

O ESPETÁCULO DOS NEGÓCIOS: The experience economy. B. Joseph Pine II e James H. Gilmore. $3^{a} \mathrm{Ed}$. Rio de Janeiro: Campus, 2003. 277 p. Uma das literaturas clássicas que ajuda a compreender 0 valor econômico das sensações e os princípios que devem ser adotados para desenvolvê-las e gerenciá-las. Os autores transferem os aprendizados da configuração de um espetáculo para o mundo dos negócios em geral. Além de apresentar a matriz da construção da experiência, eles ressaltam que criar sensações não significa entreter os clientes, mas sim gerenciar estímulos que provoquem envolvimento.

THE CUSTOMER EXPERIENCE EDGE: Technology and Techniques for Delivering an Enduring, Profitable and Positive Experience to Your Customers. Reza Soudagar; Vinay lyer e Volker G. Hildebrand. New York: McGraw-Hill, 2011. 320 p. 0 livro é um guia claro e conciso para obter insights sobre como aproveitar a experiência do cliente para conseguir uma vantagem competitiva. Escrito com 0 apoio de estudos de casos que ilustram os conceitos, permite que o leitor tenha referências em como oferecer experiências de qualidade e, conseqüentemente, a lealdade do cliente. Os autores explicam como construir a experiência do consumidor tendo como base a psicologia comportamental, microeconomia e tecnologia.

MANAGING THE CUSTOMER EXPERIENCE: Turning customers into advocates. Shaun Smith e Joe Wheeler. London: Prentice Hall, 2002. 254 p. Os autores demonstram como intensificar a satisfação dos clientes com experiências tão marcantes a ponto de transformá-los em advogados da empresa. Tendo como pilares da experiência do consumidor a tríade Marketing, Operações e Recursos Humanos, o leitor é conduzido no passo-a-passo da criação de experiência por Design, a pensar a empresa do ponto de vista do cliente e então, projetar e fornecer uma experiência que o leva à lealdade e rentabilidade.

CUSTOMER EXPERIENCE: Future trends and insights. Colin Shaw; Qaalfa Dibeehi e Steven Walden. Basingstoke: Palgrave Macmillan, 2010. 256 p. Esse é o quarto livro dos autores, que traduz suas experiências de consultoria. Apoiado em três tendências que ajudam a melhorar a experiência do cliente: compreensão dos motivadores psicológico, do avanço das mídias sociais e da neurociência, o livro apresenta uma metodologia para entender os drivers emocionais do cliente e fazer com que as empresas cumpram com a promessa da marca, consistentemente, considerando todos os pontos de contato com o consumidor.

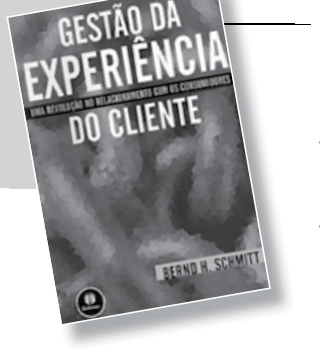

GESTÃO DA EXPERIÊNCIA DO CLIENTE: Uma revolução no relacionamento com os consumidores. Bernd H. Schmitt. Porto Alegre: Bookman, 2004. 184 p. 0 autor apresenta uma proposta de estrutura e etapas para estabelecer os processos de gestão da experiência do consumidor, criando uma ferramenta de administração do relacionamento com clientes em cada ponto de contato. A criação de uma experiência de marca única e vívida com foco no cliente passa pelo desenvolvimento da estratégia de plataforma experiencial, interações dinâmicas e inovação continua. Schmitt também é autor do livro Experiential Marketing lançado em 1999. 